\title{
Triphenylphosphonium cation: A valuable functional group for antimicrobial photodynamic therapy
}

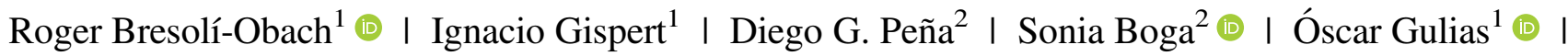

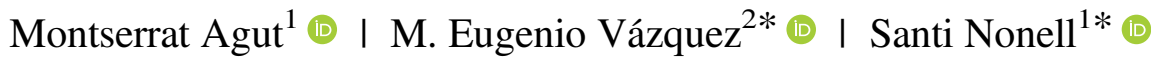

${ }^{1}$ Institut Químic de Sarrià, Universitat Ramon Llull, Barcelona, Spain

${ }^{2}$ Centro Singular de Investigación en Química Biolóxica e Materiais Moleculares (CiQUS),

Departamento de Química Orgánica, Universidade

de Santiago de Compostela, Santiago de

Compostela, Spain

*Correspondence

M. Eugenio Vázquez, Centro Singular de Investigación en Química Biolóxica e Materiais Moleculares (CiQUS), Departamento de Química Orgánica, Universidade de Santiago de Compostela, Santiago de Compostela, Spain.

Email: eugenio.vazquez@usc.es

Santi Nonell, Institut Químic de Sarrià, Universitat Ramon Llull, Via Augusta 390, 08017, Barcelona, Spain.

Email: santi.nonell@iqs.url.edu

Funding information

Consellera de Cultura, Educación e Ordenación

Universitaria, Xunta de Galicia (ES), Grant/Award

Number: ED431G/09; Fundación Asociación

Española contra el Cáncer, Grant/Award Number:

IDEAS197VAZQ; Generalitat de Catalunya,

Grant/Award Number: 2017 FI_B2 00140;

Ministerio de Economía y Competitividad, Grant/

Award Numbers: CTQ2013-49317-EXP,

CTQ2013-48767-C3-1-R,

CTQ2015-71896-REDT, CTQ2015-70698-R,

CTQ2016-78454-C2-1-R
Light-mediated killing of pathogens by cationic photosensitisers is a promising antimicrobial approach that avoids the development of resistance inherent to the use of antimicrobials. In this study, we demonstrate that modification of different photosensitisers with the tri-
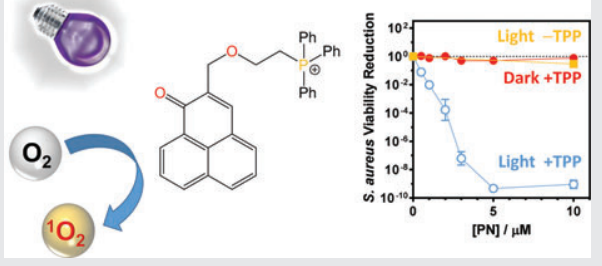
phenylphosphonium cation yields derivatives with excellent photoantimicrobial activity against Gram-positive bacteria (ie, Staphylococcus aureus and Enterococcus faecalis). Thus, the triphenylphosphonium functional group should be considered for the development of photoantimicrobials for the selective killing of Grampositive bacteria in the presence of Gram-negative species.

\section{KEYWORDS}

antibiotic resistance, antimicrobial photodynamic therapy, cationic photosensitisers, phenalenone, photoantimicrobials, reactive oxygen species, singlet oxygen, triphenylphosphonium
Infectious diseases were one of the leading causes of death until antibiotics were discovered at the beginning of the twentieth century [1]. The first antibiotic, discovered by Alexander Fleming in 1928, was penicillin, and since then many other antimicrobial agents have been developed and produced. The 1950s are considered the golden age of antimicrobials, when about forty percent of all currently used agents were discovered [2]. Despite their success, the abuse and misuse of antimicrobials has led to the selection of multiresistant pathogens, which poses a serious public health

Roger Bresolí-Obach, Ignacio Gispert and Diego García Peña contributed equally to this study. hazard. Indeed, in February 2017, the World Health Organization published the first-ever list of "priority pathogens for research and development of new antibiotics" [3]. The cost of producing new antimicrobials and the serious threat of bacteria developing resistance to them has acted as a barrier against further investments in this field. The major cause for onset of resistance is the mode of action of most drugs, which act against single molecular targets [4].

Consequently, alternative therapies that can treat infections under a different paradigm need to be actively researched. Among them, antimicrobial photodynamic therapy (aPDT), shows highly promising results $[5,6]$. In this therapy, a drug activated by light, a photoantimicrobial- 
also called a photosensitiser, PS - causes extensive oxidative damage compromising the pathogen viability. Specifically, upon absorption of light energy, photoantimicrobials are promoted to higher-energy electronic excited states from which they produce cytotoxic reactive oxygen species (ROS) such as singlet oxygen $\left({ }^{1} \mathrm{O}_{2}\right)$, superoxide, hydrogen peroxide or hydroxyl radicals [7].

It is now commonly accepted that positively-charged PSs show better results than neutral or negatively-charged ones, owing to their favorable electrostatic interaction with the bacterial cell wall [8]. Thus, the most common photoantimicrobials bear one or more positive charges, for example, methylene blue or 5,10,15,20-tetrakis(1-methyl-4-pyridinio)porphyrin [9-11].

Phenalenones are small aromatic ketones that produce ROS with high-yields upon exposure to UVA, violet, or blue light. Thus, the unsubstituted phenalenone (1, Scheme 1) produces ${ }^{1} \mathrm{O}_{2}$ with quantum yield $\Phi_{\Delta}=1$ [12-15]. Phenylphenalenones are abundant in nature, for example, as plant phytoalexins and phytoanticipins [16-18], and we have previously demonstrated that phenylphenalenones isolated from Fusarium oxysporum-infected banana plants showed enhanced antifungal activity under exposure to UVA, which led us to propose them as a light-induced component in the defense armor of these plants against fungal pathogens [19,
20]. Details of their photochemistry have recently been clarified [21]. Given the excellent photosensitising properties of phenalenone, it is not surprising that cationic derivatives have been prepared appending ammonium, anilinium, pyridinium (SAPYR), or guanidinium (SAGUA) moieties to its structure. Among them, SAPYR and SAGUA showed the highest potential for blue-light aPDT (Scheme 1) [22, 23].

Inspection of the photoantimicrobials reported so far reveals that the potential of the important cationic group triaryl phosphonium for antimicrobial PDT has not been investigated so far. Triphenylphosphonium (TPP) cations have a large hydrophobic surface area and delocalized charge distribution that results in weakened solvation enthalpy, which allows them to easily cross the biological membranes of eukaryotic cells [24, 25]. Once inside the cell, TPPs are driven to the mitochondria by the large electrochemical potential generated by the electron transport chain [26]. TPPs have become valuable tools in mitochondrial medicine, as targeting units in a number of mitochondriatargeted drugs and ROS modulators [27-31]. Given the similarities between mitochondria and bacteria [32], we set out to assess the potential of TPP as a targeting unit for the development of new photoantimicrobials. Herein, we report the synthesis of (2-((1-oxo- $1 H$-phenalen-2-yl)methoxy) ethyl) triphenylphosphonium bromide, $\mathrm{PNPPh}_{3}{ }^{+}$(5);<smiles>[R]C1=Cc2cccc3cccc(c23)C1=O</smiles>

1, phenalenone, $\mathrm{R}=\mathrm{H}$<smiles>[R]C=[Y9]([H])N1C=CC=CC1</smiles><smiles>CN(C=CC(C)(C)C)C(N)=[OH+]</smiles><smiles>O=C1C(CCl)=Cc2cccc3cccc1c23</smiles>

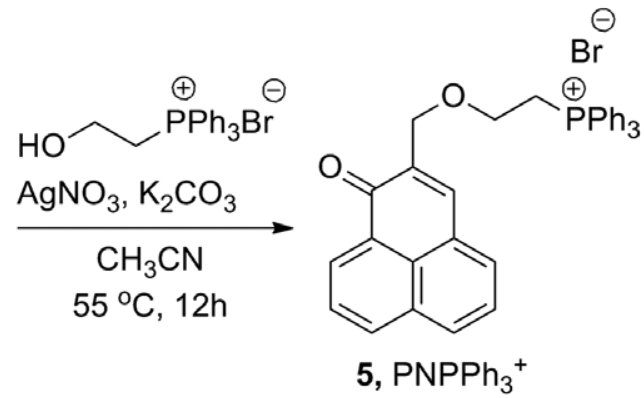

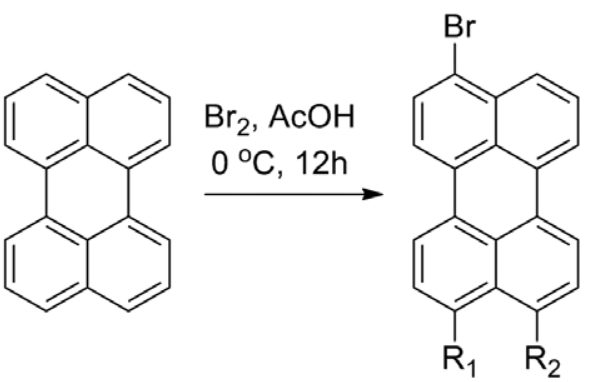

$\mathrm{PPh}_{3}, \mathrm{Pd}_{2}(\mathrm{dba})_{3}$ ethyleneglycol

$135^{\circ} \mathrm{C}, 60 \mathrm{~h}, 53 \%$<smiles>[R2]c1ccc2c3cccc4c([Pb])ccc(c5ccc([R])c1c25)c43</smiles>

7, $\mathrm{R}_{1}=\mathrm{H}, \mathrm{R}_{2}=\mathrm{Br}$

8, $\mathrm{R}_{1}=\mathrm{Br}, \mathrm{R}_{2}=\mathrm{H}$

9, $\mathrm{R}_{1}=\mathrm{H}, \mathrm{R}_{2}=\mathrm{PPh}_{3}^{\oplus}$ 10, $\mathrm{R}_{1}=\mathrm{PPh}_{3}, \mathrm{R}_{2}=\mathrm{H}$

SCHEME 1 Top. Structure of phenalenone (1) and some of its cationic derivatives. Middle. Synthesis of the triphenylphosphonium derivative $\mathrm{PNPh}_{3}{ }^{+}(\mathbf{5})$. Bottom. Synthesis of the perylene-3,9(10)-diylbis(triphenylphosphonium) derivatives, $(\mathbf{9 , 1 0})$ 
together with the study of its optical, photophysical and photoantimicrobial properties against Gram-positive and Gram-negative microbial cells in vitro. In addition, to further demonstrate the value of the TPP group for the development of new compounds with photoantibacterial properties, we also synthetized and tested the perylene-3,9(10)-diylbis(triphenylphosphonium) derivatives $(\mathbf{9 , 1 0})$, which, in contrast to phenalenone, are highly fluorescent but poor ${ }^{1} \mathrm{O}_{2}$ photosensitisers [33].

The TPP derivative of phenalenone was obtained following the straightforward procedure outlined below (Scheme 1). The first step involved the reaction of commercial $1 H$-phenalen-1-one (1) with $p$-formaldehyde in acidic media to yield the electrophilic intermediate 4. Nucleophilic substitution of this chloride with 2-(hydroxyethyl)triphenylphosphonium bromide afforded the desired product $\left(\mathrm{PNPPh}_{3}{ }^{+}, \mathbf{5}\right)$ in modest yield, presumably due to the low nucleophilicity of the hydroxyl group and the competitive formation of phosphine oxides. On the other hand, the perylene derivatives were obtained through a simple two-step synthesis involving bromination of perylene, which led to an inseparable mixture of 3,9-and 3,10- dibromides [34], followed by a palladium-catalized cross coupling with triphenylphosphine that led to the corresponding bis(TPP) derivatives, also as an inseparable mixture of 3,9- and 3,10isomers $(\mathbf{9 , 1 0}$, Scheme 1, bottom) [35].

Having at hand the desired TPP derivatives, we first studied their photophysical properties. 5 displayed absorbance maxima at $363 \mathrm{~nm}\left(\varepsilon=8900 \mathrm{M}^{-1} \mathrm{~cm}^{-1}\right)$ and $400 \mathrm{~nm}\left(\varepsilon=7200 \mathrm{M}^{-1} \mathrm{~cm}^{-1}\right.$; Figure 1A), which enabled the use of UVA, violet or blue light sources for its photoexcitation. In agreement with the properties of phenalenone, the TPP-derivative (5) is weakly fluorescent (quantum yield $\Phi_{\mathrm{F}}=0.015$ in PBS; Figure S1 in Appendix S1, Supporting Information) and the emission spectrum shows a maximum at $494 \mathrm{~nm}$. More importantly, $\mathbf{5}$ shows a high ability to produce $\operatorname{ROS}\left(\Phi_{\Delta}=0.73\right.$ in PBS; Figure 1B) and high photostability, losing less than $30 \%$ of its absorbance after being exposed to a fluence of $50 \mathrm{~J} \cdot \mathrm{cm}^{-2}$ at $420 \mathrm{~nm}$ (Figure S2 in Appendix S1). This fluence is $\sim 40$-fold larger than that needed to inactivate bacteria (see below). In turn, the perylene derivatives $(\mathbf{9 , 1 0})$ present a broad absorbance band between 400 and $500 \mathrm{~nm}$ with an absorbance maximum at $467 \mathrm{~nm}\left(\varepsilon=32000 \mathrm{M}^{-1} \mathrm{~cm}^{-1}\right.$; Figure 1C). Consistent with the photophysical properties of perylene, the bis(TPP) perylene derivatives $(\mathbf{9 , 1 0})$ remain highly fluorescent $\left(\Phi_{\mathrm{F}}=0.98\right.$ in PBS; Figure S3 in Appendix S1) with a maximum at $508 \mathrm{~nm}$, and are poor ${ }^{1} \mathrm{O}_{2}$ photosensitisers $\left(\Phi_{\Delta}=0.034\right.$ either in PBS or in deuterated-PBS, 21-fold less than the phenalenone derivative (5); Figure 1D). Phenalenones are generally regarded as pure ${ }^{1} \mathrm{O}_{2}$ photosensitisers. The production of other ROS such as superoxide and its secondary products hydrogen peroxide and hydroxyl radicals has been
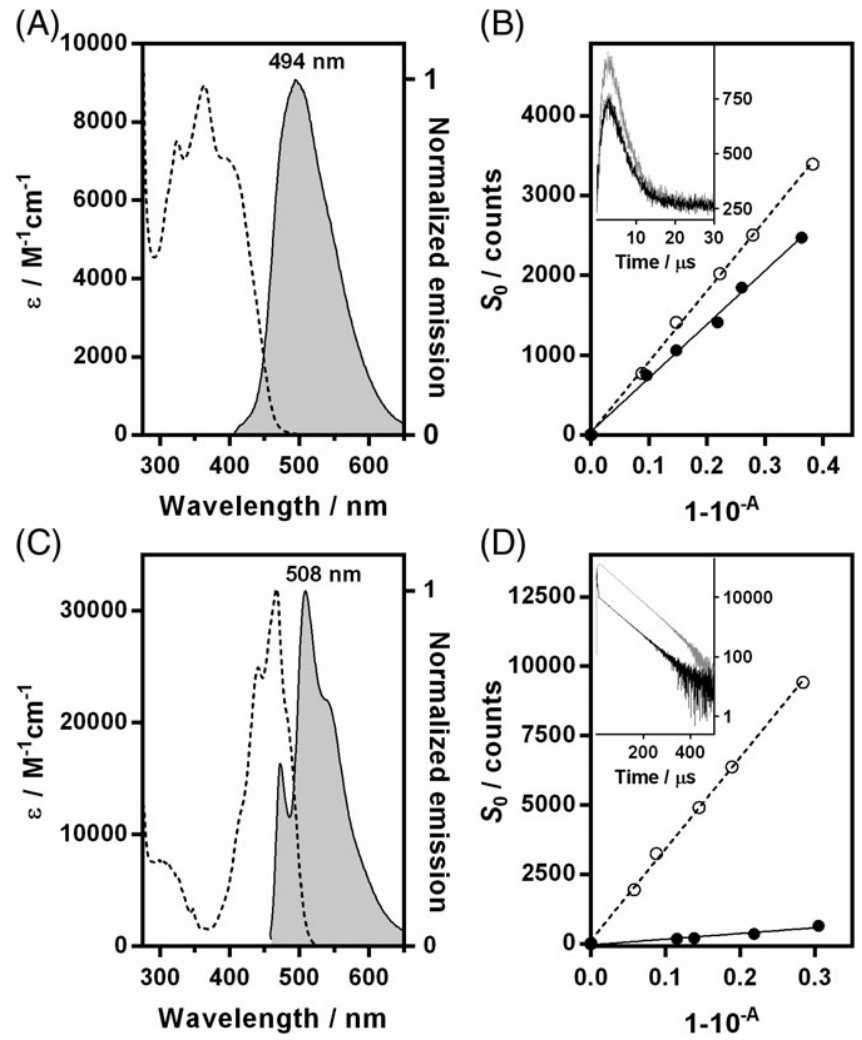

FIGURE 1 Left. Absorption (dashed line) and emission (solid line, filled curve) spectra of (5) (A) and $(\mathbf{9 , 1 0})(C)$ in phosphate buffered saline (PBS, $\mathrm{pH}$ 7.4). Right. Determination of ${ }^{1} \mathrm{O}_{2}$ quantum yields $\left(\Phi_{\Delta}\right.$ dependence of the ${ }^{1} \mathrm{O}_{2}$ phosphorescence intensity $\left(S_{0}\right)$ on the sample absorption factor (1-10 ${ }^{-\mathrm{A}}$; see Supporting Information in Appendix S1) for $(\mathbf{5})$ or $(\mathbf{9 , 1 0})$ (B or D, respectively; solid line) and the reference PNS or flavin mononucleotide (dashed line; $\Phi_{\Delta}=0.97$ and 0.56 , respectively) in PBS; $\lambda_{\text {exc }}=355$ and $473 \mathrm{~nm}$, respectively. Inset: Kinetic traces for ${ }^{1} \mathrm{O}_{2}$ phosphorescence signals for optically matched samples of the PNS (grey) and (5) (black) (B) or flavin mononucleotide (grey) and (9,10) (black) (D). Due to the low $\Phi_{\Delta}$ of $(\mathbf{9 , 1 0})$, the optically matched traces for inset D were recorded in deuterated-PBS and plotted in logarithmic scale to obtain a clearer kinetic trace. When performing ${ }^{1} \mathrm{O}_{2}$ experiments, it is often advantageous to record data in a deuterated solvent to exploit the large H/D solvent isotope effect on the ${ }^{1} \mathrm{O}_{2}$ lifetime $\left(\tau_{\Delta}(\mathrm{D})>>\tau_{\Delta}(\mathrm{H})\right.$; ie, $66 \mu$ s for $\mathrm{D}_{2} \mathrm{O}$ vs $3.5 \mu$ s for $\mathrm{H}_{2} \mathrm{O}$ ) and ${ }^{1} \mathrm{O}_{2}$ radiative rate constant [36]

investigated for $\mathbf{5}$ and $\mathbf{9 , 1 0}$ and confirmed to be negligible in aqueous solution (Figure S4 in Appendix S1).

The aPDT activity of both $\mathbf{5}$ and the $\mathbf{9 , 1 0}$ mixture was tested against two different Gram-positive bacteria, Staphylococcus aureus and Enterococcus faecalis and one Gramnegative species, Escherichia coli. Bacterial cell suspensions were incubated in the dark at $37^{\circ} \mathrm{C}$ for 10 minutes with $\mathbf{5}$ or 9,10 at concentrations ranging from 0.5 to $10 \mu \mathrm{M}$ for $S$. aureus and E. faecalis and from 1 to $50 \mu \mathrm{M}$ for E. coli. After the incubation period, they were irradiated with blue light (420 nm for $\mathbf{5}$ and $463 \mathrm{~nm}$ for $\mathbf{9 , 1 0}$ for optimum spectral overlap, Figure S5 in Appendix S1). To better assess the effect of the cationic moiety TPP, the neutral $1 H$-phenalen1-one (PN), the anionic 1H-phenalen-1-one-2-sulphonate (PNS) and the neutral unsubstituted perylene were used as controls. 5 showed strong photoantimicrobial activity against 

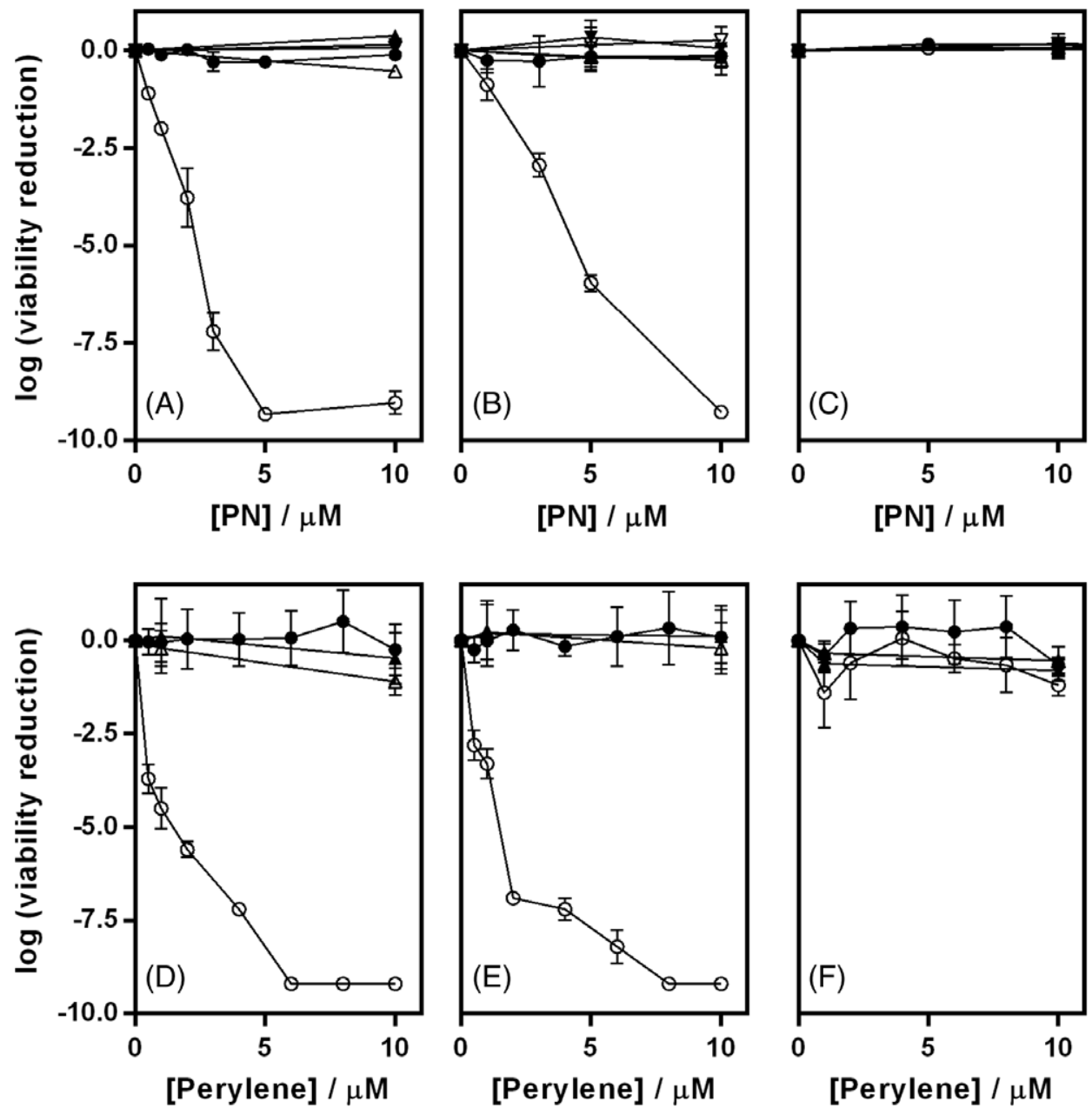

FIGURE 2 Survival curves of Staphylococcus aureus (A/D), Enterococcus faecalis (B/E) and Escherichia coli (C/F). (A-C) Incubated with different concentrations of 5 (circles), PN (up triangle) and PNS (down triangle) in the dark (closed symbols) and irradiated with blue light (420 $\pm 10 \mathrm{~nm} ; 1.2 \mathrm{~J} \cdot \mathrm{cm}^{-2}$; open symbols). (D-F) Incubated with different concentrations of $\mathbf{9 , 1 0}$ (circles) and the parent perylene (up triangle) in the dark (black symbols), and irradiated with blue light $\left(463 \pm 11 \mathrm{~nm} ; 10 \mathrm{~J} \cdot \mathrm{cm}^{-2}\right.$; open symbols)

both $S$. aureus and E. faecalis at the very low-light fluence of $1.2 \mathrm{~J} \cdot \mathrm{cm}^{-2}$ in a concentration-dependent manner (Figure 2). For $S$. aureus, a remarkable viability reduction of $9 \log _{10}$ was achieved at a concentration of $5 \mu \mathrm{M}$, whereas a reduction of at least $\geq 3 \log _{10}$ (99.9\% reduction), considered biologically relevant in the guidelines of hand hygiene [37], was observed already at $2 \mu \mathrm{M}$. The results for E. faecalis were similar, $10 \mu \mathrm{M}$ being required to achieve $9 \log _{10}$ reduction and $3 \mu \mathrm{M}$ to achieve $3 \log _{10}$. In addition, 5 did not induce any dark toxicity in any of these bacteria, even at the highest concentration tested. Compared with the reported results for the pyridinium-substituted SAPYR and the guanidinium-substituted SAGUA [22, 23], the efficiency of 5 makes it a very promising photoantimicrobial agent. On the other hand, neutral PN and anionic PNS, which show higher $\Phi_{\Delta}$ values than 5 [12-15], did not kill $S$. aureus or E. faecalis to any measurable extent, thus confirming the strong (and selective) targeting effect of the cationic TPP unit (Figure 2).

To further characterize the effect of the TPP targeting group, the photoinactivation experiments were repeated with the perylenes. As was the case with phenalenone, no photoantimicrobial effect was observed for the neutral unsubstituted perylene. On the other hand, the photoinactivation results with the TPP perylene derivatives $(\mathbf{9 , 1 0})$ were very similar to those of the phenalenone derivative 5: concentrations of $<0.5 \mu \mathrm{M}$ and $6 \mu \mathrm{M}$ for $S$. aureus and $<1 \mu \mathrm{M}$ and $8 \mu \mathrm{M}$ for $E$. faecalis were enough to achieve $\geq 3$ - and $9-\log _{10}$ reduction in CFUs. Since the quantum yield of singlet oxygen production by $\mathbf{9 , 1 0}$ is 21 -fold smaller than for $\mathbf{5}$, we used a 8 -fold higher light fluence $\left(10 \mathrm{~J} \cdot \mathrm{cm}^{-2}\right)$ to be able to compare the two photosensitisers. Combined with 3-fold larger absorption coefficients for the perylenes, comparable amounts of singlet oxygen were produced by the two photosensitisers. Thus, TPP has the ability to endow very different photosensitisers with similar photoantimicrobial activity, which confirms the importance of targeting in aPDT.

On the other hand, and in contrast with the nitrogenbased phenalenone derivatives, $\mathbf{5}$ and the $\mathbf{9 , 1 0}$ perylene mixture were ineffective against $E$. coli up to $50 \mu \mathrm{M}$ (Figure 2). The neutral PN and perylene, as well as the anionic PNS, did not cause any measurable cell death either. This suggests 
that TPP-modified photosensitizers are too hydrophobic to penetrate the lipopolysaccharide barrier in Gram-negative bacteria, which is consistent with the negative results observed previously for TPP-modified conventional antibiotics [38, 39]. Taken together, the two sets of results indicate that singlet oxygen production by photoantimicrobials at the external lipopolysaccharide layer is totally ineffective for killing $E$. coli cells.

In order to rationalize these observations, ${ }^{1} \mathrm{O}_{2}$ production by 5 was studied for the three tested microorganisms under the same conditions as those used for the photoinactivation assays (see ESI for further details). For the three-bacterial species tested, the time-resolved near-IR ${ }^{1} \mathrm{O}_{2}$ phosphorescence signals showed similar kinetics of formation and decay (Figure S6; Table S1 in Appendix S1). This suggests that the microenvironment of the photosensitiser where ${ }^{1} \mathrm{O}_{2}$ is generated is similar for the three strains, which is surprising given the different structure of their cell walls. The kinetic rate constants were indistinguishable from those in a bacteria-free PBS solution, suggesting that $\mathbf{5}$ is in the external part of the cell wall in all cases. When a bacterial cell suspension was centrifuged and the supernatant and pellet tested separately for ${ }^{1} \mathrm{O}_{2}$ phosphorescence, ${ }^{1} \mathrm{O}_{2} \quad$ was observed in the supernatant but not in the resuspended pellet (Figure S7 in Appendix S1), indicating that the interaction between $\mathbf{5}$ and the bacterial cell wall is rather weak in all cases. This was confirmed by absorption spectroscopy, which showed the presence of $\mathbf{5}$ only in the supernatant (Figure S8 in Appendix S1).

To sum up, two different triphenylphosphonium photosensitizers have been synthetized. On one hand, a new cationic phenalenone derivative, $\mathbf{5}$, is weakly fluorescent and shows a high capacity to produce ${ }^{1} \mathrm{O}_{2}$ and high photostability. On the other hand, the TPP derivatives of perylene are highly fluorescent and a weak ${ }^{1} \mathrm{O}_{2}$ generators. Despite their opposite photophysical profiles, both $\mathbf{5}$, and the perylene derivatives are highly phototoxic against Gram-positive $S$. aureus and E. faecalis but ineffective against Gram-negative E. coli. These results, combined with their negligible dark toxicity and affordable synthesis, suggest that cationic triphenylphosphonium photosensitisers should be considered as photoantimicrobials in situations where selective killing of Gram-positive bacteria in the presence of Gram-negative species could be of therapeutic value.

\section{ACKNOWLEDGMENTS}

This work has been supported by grants CTQ2013-49317EXP， CTQ2013-48767-C3-1-R， CTQ2015-71896-REDT, CTQ2015-70698-R and CTQ2016-78454-C2-1-R from the Spanish Ministerio de Economía y Competitividad, R.B.-O. thanks the European Social Funds and the SUR del DEC de la Generalitat de Catalunya for a predoctoral fellowship (2017 FI_B2 00140). Financial support from the Xunta de Galicia
(Centro singular de investigación de Galicia accreditation 2016-2019, ED431G/09) and the European Union (European Regional Development Fund-ERDF), is gratefully acknowledged. We finally wish to thank the Fundación AECC for their generous support (IDEAS197VAZQ).

\section{ORCID}

Roger Bresolí-Obach (D) http://orcid.org/0000-0002-7819-7750

Sonia Boga (D) http://orcid.org/0000-0001-7105-6077

Óscar Gulias (D) http://orcid.org/0000-0001-8432-1108

Montserrat Agut (D) http://orcid.org/0000-0001-9173-9684

M. Eugenio Vázquez (D) http://orcid.org/0000-0001-7500-985X

Santi Nonell (D) http://orcid.org/0000-0002-8900-5291

\section{REFERENCES}

[1] MMWR Morb, Mortal Wkly Rep. 1999, 48, 621.

[2] J. Bérdy, J. Antibiot. (Tokyo) 2012, 65, 441.

[3] WHO, http://www.who.int/en/news-room/detail/27-02-2017-who-publisheslist-of-bacteria-for-which-new-antibiotics-are-urgently-needed (Accessed September 2017).

[4] K. Lewis, Nat. Rev. Drug Discov. 2013, 12, 371.

[5] M. R. Hamblin, T. Hassan, Photochem. Photobiol. Sci. 2004, 3, 436.

[6] M. Wainwright, T. Maisch, S. Nonell, K. Plaetzer, A. Almeida, G. P. Tegos, M. R. Hamblin, Lancet Infect. Dis. 2017, 17, e49.

[7] C. Foote, Photochem. Photobiol. 1991, 54, 659.

[8] A. Minnock, D. I. Vernon, J. Schofield, J. H. Parish, S. B. Brown, Antimicrob. Agents Chemother. 2000, 44, 522 .

[9] M. Wainwright, D. A. Phoenix, J. Marland, D. R. A. Wareing, F. J. Bolton, FEMS Immunol. Med. Microbiol. 1997, 19, 57.

[10] M. Merchat, G. Bertolini, P. Giacomini, A. Villanueva, G. Jori, J. Photochem. Photobiol. B: Biol. 1996, 32, 153.

[11] M. Wilson, J. Appl. Bacteriol. 1993, 75, 299

[12] E. Oliveros, P. Suardi-Murasecco, T. Aminian-Saghafi, A. M. Braun, H. -J. Hansen, Helv. Chim. Acta 1991, 74, 79.

[13] R. Schmidt, C. Tanielian, R. Dunsbach, C. Wolff, J. Photochem. Photobiol. A Chem. 1994, 79, 11.

[14] S. Nonell, M. González, F. R. Trull, Afinidad 1993, 44, 445.

[15] C. Martí, O. Jürgens, O. Cuenca, M. Casals, S. Nonell, J. Photochem. Photobiol. A Chem. 1996, 97, 11.

[16] J. G. Luis, W. Q. Fletcher, F. Echeverri, T. A. Grillo, Tetrahedron 1994, 50,10963

[17] F. Otálvaro, J. Nanclares, L. E. Vásquez, W. Quiñones, F. Echeverri, R. Arango, B. Schneider, J. Nat. Prod. 2007, 70, 887.

[18] A. López-Arencibia, M. Reyes-Batlle, M. B. Freijo, G. McNaughton-Smith, P. Martín-Rodríguez, L. Fernández-Pérez, I. Sifaoui, C. Wagner, A. B. García-Méndez, A. R. Liendo, C. J. Bethencourt-Estrella, T. A. Grillo, J. E. Piñero, J. Lorenzo-Morales, Exp. Parasitol. 2017, 183, 218.

[19] A. Lazzaro, M. Corominas, C. Martí, C. Flors, L. R. Izquierdo, T. A. Grillo, J. G. Luis, S. Nonell, Photochem. Photobiol. Sci. 2004, 3, 706.

[20] C. Flors, S. Nonell, Acc. Chem. Res. 2006, 39, 293.

[21] G. Bucher, R. Bresolí-Obach, C. Brosa, C. Flors, J. G. Luis, T. A. Grillo, S. Nonell, Phys. Chem. Chem. Phys. 2014, 16, 18813.

[22] A. Späth, C. Leibl, F. Cieplik, K. Lehner, J. Regensburger, K. A. Hiller, W. Bäumler, G. Schmalz, T. Maisch, J. Med. Chem. 2014, 57, 5157.

[23] T. Maisch, A. Späth, I. Tabenski, F. Cieplik, L. Tabenski, J. Regensburger, K.-A. Hiller, W. Buchalla, Photochem. Photobiol. Sci. 2016, 15, 57.

[24] V. P. Skulachev, A. E. Liberman, V. P. Topali, L. M. Tsofina, A. A. Jasaitis, V. P. Skulachev, Nature 1969, 222, 1076

[25] M. F. Ross, G. F. Kelso, F. H. Blaikie, A. M. James, H. M. Cochemé, A. Filipovska, T. Da Ros, T. R. Hurd, R. A. J. Smith, M. P. Murphy, Biochem. Mosc. 2005, 70, 222.

[26] R. A. J. Smith, C. M. Porteous, A. M. Gane, M. P. Murphy, Proc. Natl. Acad. Sci. U.S.A. 2003, 100, 5407.

[27] J. Neuzil, L. F. Dong, J. Rohlena, J. Truksa, S. J. Ralph, Mitochondrion 2013, 13, 199. 
[28] L. Dong, J. Neuzil, B. Yan, M. Stantic, R. Zobalova, A. Bezawork-Geleta M. Stapelberg, J. Stursa, K. Prokopova, BMC Cancer 2015, 15, 401.

[29] M. P. Murphy, R. A. J. Smith, Adv. Drug Deliv. Rev. 2000, 41, 235.

[30] M. P. Murphy, R. A. J. Smith, Annu. Rev. Pharmacol. Toxicol. 2007, 47, 629 .

[31] R. A. J. Smith, R. C. Hartley, M. P. Murphy, Antioxid. Redox Signal. 2011, 15,3021 .

[32] W. F. Martin, M. Mentel, Nat. Educ. 2010, 3, 58.

[33] N. Soh, T. Ueda, Talanta 2011, 85, 1233.

[34] P. Schlichting, U. Rohr, K. Müllen, Liebigs Ann. Recueil 1997, 72, 395.

[35] D. Marcoux, A. B. Charette, J. Org. Chem. 2008, 73, 590.

[36] P. R. Ogilby, C. S. Foote, J. Am. Chem. Soc. 1981, 103, 1219.

[37] J. Boyce, D. Pittet, Infect. Control Hosp. Epidemiol. 2002, 23, S3.

[38] N. Hirota, S. Matsuura, N. Mochizuki, N. Mutoh, Y. Imae, J. Bacteriol. 1981, 148, 399.

[39] E. A. Dunn, M. Roxburgh, L. Larsen, R. A. J. Smith, A. D. McLellan, A. Heikal, M. P. Murphy, G. M. Cook, Bioorg. Med. Chem. 2014, 22, 5320.

\section{SUPPORTING INFORMATION}

Additional supporting information may be found online in the Supporting Information section at the end of the article.

Appendix S1. Supplementary information

Figure S1. Determination of fluorescence quantum yield for $\mathrm{PNPPh}_{3}{ }^{+}$(reference $=$quinine sulphate; solvent $=\mathrm{H}_{2} \mathrm{SO}_{4}$ $\left.1 \mathrm{~N} ; \Phi_{\mathrm{F}}=0.54 ; \lambda_{\text {exc }}=360 \mathrm{~nm}\right)^{7}$

Figure S2. Changes in $\mathrm{PNPPh}_{3}{ }^{+}$absorbance spectrum upon blue light irradiation $(420 \pm 10 \mathrm{~nm})$. Bleaching of the absorbance at $368 \mathrm{~nm}$ at different blue light fluence

Figure S3. Determination of fluorescence quantum yield for the mixture 9,10 (reference $=\mathrm{FMN}$; solvent $=\mathrm{PBS} ; \Phi_{\mathrm{F}}=$ $\left.0.25 ; \lambda_{\text {exc }}=450 \mathrm{~nm}\right)^{8,9}$

Figure S4. Fluorescence enhancement of DHE sensitized by 5 and 9,10 in function of the light fluence $\left(\lambda_{\text {irr }}=420 \pm 10\right.$ $\mathrm{nm})$. Considering a superoxide radical anion quantum yield of 1 and negligible photobleaching of $\mathbf{5}$ and $\mathbf{9 , 1 0}$, the gener- ated $\mathrm{O}_{2}{ }^{\bullet-}$ should correspond to a concentration of 7.5, 15 and $30 \mathrm{mM}$ at light fluences of 3,6 and $12 \mathrm{~J} / \mathrm{cm}^{2}$, respectively. Photoconversion of DHE in absence of 5 and 9,10 was carried out as negative control and oxidation of DHE by $0.5 \mathrm{mM} \mathrm{KO}_{2}$ in darkness was carried out as positive control. Hydrogen peroxide and hydroxyl radicals are secondary photochemical products of superoxide, therefore it can be safely anticipated that their production is negligible, too

Figure S5. Top: Emission spectra of the LZC-420 at $420 \mathrm{~nm}$ (blue) and the absorbance spectrum of $\mathrm{PNPPh}_{3}{ }^{+}$ (red). Bottom: Emission spectra of the LED Par 64 Short V2 lamp blue led at $463 \mathrm{~nm}$ (blue) and the absorbance spectrum of the inseparable mixture of $\mathbf{9 , 1 0}$ (red)

Figure S6. ${ }^{1} \mathrm{O}_{2}$ phosphorescence decay signals for the three bacterial species (E. faecalis, S. aureus and E. coli represented with green, black and red line, respectively) before centrifugation

Figure S7. ${ }^{1} \mathrm{O}_{2}$ phosphorescence kinetics decay for $\mathrm{PNPPh}_{3}{ }^{+}$(left) and reference PNS (right) in S. aureus (top), E. faecalis (middle), E. coli (down)

Figure S8. Absorption spectra of the supernatant (blue) and of the pellet resuspended in fresh PBS (black) in S. aureus (top), E. faecalis (middle), E. coli (down) previously incubated with $10 \mu \mathrm{M} 5$

How to cite this article: Bresolí-Obach R, Gispert I, Peña DG, et al. Triphenylphosphonium cation: A valuable functional group for antimicrobial photodynamic therapy. J. Biophotonics. 2018;11:e201800054. https://doi.org/10.1002/jbio.201800054 